\title{
AN EXPERIMENTAL EVALUATION OF FIBER REINFORCED POLYPROPYLENE THERMOPLASTICS FOR AEROSPACE APPLICATIONS
}

\author{
K.Vijaya Kumar ${ }^{1 *}$, Mir Safiulla ${ }^{2}$ and A.N. Khaleel Ahmed ${ }^{3}$ \\ ${ }^{1}$ Hindustan Aeronautics Limited, Bangalore, India \\ ${ }^{2}$ Department of Mechanical Engineering, Ghousia College of Engineeringg, Ramnagaram, Bangalore, India \\ ${ }^{3}$ Department of Mechanical Engineering,Vivekananda Institute of Technology, Bangalore, India \\ "Corresponding e-mail: vijaykmr3764@gmail.com
}

\begin{abstract}
Fiber reinforced thermosetting composites have wide scope in the field of Aerospace and Military Applications. These materials exhibit high strength and high stiffness, besides these composites have long fatigue life, corrosion resistance, environmental stability, thermal insulation and conductivity. Researchers are exploring possibilities to use natural fiber reinforced polymer composites (NFRPCs) in response to the increasing demand for environmentally friendly materials and also to develop reusable fiber reinforced thermoplastics with the desire to reduce the cost and to promote the replacement of thermosetting composites.

In this work efforts are put to fabricate fiber thermoplastics made of jute, glass and carbon with (PP) polypropylene as the matrix. The mechanical strength of these fiber reinforced thermoplastics was evaluated and compared with that of fiber reinforced thermosetting polymers made of same fibers along with epoxy matrix. The tests clearly indicate that the laminates made of fiber reinforced polypropylene have 7 to 8 times less strength compared to thermosetting polymers made of fiber epoxy and it is found that for achieving better strength of the material, the polypropylene layers should be more than that of the epoxy matrix or to use alternative thermoplastic materials like polyphenylene sulfide (PPS), polyetherimide (PEI) and polyetheretherketone (PEEK). Hence these materials are feasible for fabricating low load bearing aircraft interior cabin parts and automobile interiors which can be reused or reshaped making them easy to re-work and repair.
\end{abstract}

Keywords: Carbon fiber, Jute fiber, Polypropylene Thermoplastics, Thermosetting polymers.

\section{INTRODUCTION}

The aerospace composite parts are mainly manufactured with thermoset resins as matrix; these thermoset polymers are generally associated with high initial costs, long process cycles and subsequently tend to increase the cost of production. From a material side, thermosets are cross-linked when heated and cannot be re-melted or re-formed, while thermoplastics are high molecular weight polymers which allow the thermoplastic resin to be readily re-melted and re-formed. It is for this reason that thermoplastics have great appeal as composite matrices.

Much research has been focused on the development of thermoplastics, especially in the areas of thermoplastic pre-pregs (fibres pre-impregnated with the thermoplastic matrix material), manufacturing techniques and joining methods.

Since thermoplastic resins do not cure via a chemical reaction they do not have to be stored in freezers. The thermoplastic is already "cured" to begin with and is formed into the final net shape as required using heat and pressure. So it has an infinite shelf life as a big advantage.

Polypropylene (PP), also known as polypropene, is a thermoplastic polymer used in a wide variety of applications including packaging and labeling, textiles (e.g., ropes, thermal underwear and carpets), stationery, plastic parts and reusable containers of various types, laboratory equipment, loudspeakers, automotive components, and polymer banknotes. An addition polymer made from the monomer propylene, it is rugged and unusually resistant to many chemical solvents, bases and acids.

Polypropylene is the second most important plastic with revenues expected to exceed US $\$ 145$ billion by 2019 . The demand for this material was growing at a rate of $4.4 \%$ per year between 2004 and 2012

In 1982, 8\% of the Airbus A130 consisted of composites. Twenty years later, the use of composites in the Airbus A380 rose to $25 \%$. In the next generation of aircraft, the use of composites is expected to hit $50 \%$ - Airbus A350 will be 53 percent composite and Boeing 787 will be more than 50 percent composite.

The incorporation of light weight plastic and composite materials in commercial aerospace vehicles is becoming a common design practice for reducing vehicle weight and achieving fuel savings. Early aircraft interior cabins were typically sheet metal, with any number of fabrics, foams and plastic materials in different locations. Today, metallic

Journal of Mechanical Engineering, Vol. ME 43, No. 2, December 2013 Transaction of the Mechanical Engineering Division, The Institution of Engineers, Bangladesh 
structures are being replaced by composites for vehicle weight reduction and resultant fuel savings.

Aerospace companies and the researchers are exploring the possibilities of replacing the thermosetting components with thermoplastics like. Lockheed Aeronautical Systems Company has used thermoplastics in the manufacture of an aircraft door structure $^{1}$. Practical cases of in-service use of thermoplastics include a trial by Lockheed of a carbon/PEEK thermoplastic composite undercarriage door on a C-130 aircraft.

A variety of demonstrator parts have also been manufactured from polyphenylene sulfide (PPS) resin by the Phillips Petroleum Company ${ }^{2}$. The technique of thermoforming was employed. This technique utilises existing technology which has been used to produce flat reinforced thermoplastic sheets.

Another demonstrator part made by Lockheed is the thermoplastic composite fighter fuselage. A section of the fuselage measuring $122 \mathrm{~cm}$ long by $137 \mathrm{~cm}$ diameter was manufactured using a variety of thermoplastic prepreg materials including AS4/PEEK ${ }^{3}$. There are many more examples of the use of thermoplastics including a landing gear strut door and access panel for the F-5F aircraft, a Hercules radome, parts of the B-2 Bomber and the nose-wheel door for the Fokker-50 aircraft all of which are described in ${ }^{4}$.

Beier et $\mathrm{al}^{5}$ have studied on the use of thermoplastic stitching yarns such as polyamide and phenoxy resins that either melt or soften during performing. The experimental results presented in this study indicated a generally high mechanical property level for stitched composites as compared to the non stitched cabon fiber layers. Katsirpoulous et $\mathrm{al}^{6}$ have analyzed the mechanical behavior of poly-ether-ether-ketone/carbon, a thermoplastic composite material. The tensile and compression behavior was studied. From this experiment it is proved that the thermoplastic composites yields better strength. Mahieux ${ }^{7}$ has suggested a cost effective manufacturing process of thermoplastic matrix composites. Hot pressing and winding of short fiber and continuous fiber reinforced thermoplastic were compared. His experiment proved that these thermoplastics can be manufactured by hot pressing.

The aim of this work is to fabricate thermoplastic composites made of carbon, glass and jute fibers mixed with polypropylene matrix and to compare its results with the existing thermosetting epoxy composites and also to assess the possibilities of using this thermoplastic polypropylene (PP) matrix as replacement for the currently used epoxies in aerospace applications.

\section{EXPERIMENTAL WORK}

The Laminates are prepared by hand layup method and cured in hot platen press. The materials used for preparing the laminates are:

1. Polypropylene film of thickness 50 microns

2. Dry Glass fibers - GF92110 (0.25 mm thick).

3. Dry Carbon Fibers-CC236 ( $0.25 \mathrm{~mm}$ thick.)

4. Jute fibers $-0.50 \mathrm{~mm}$ thick.

5.Hexcel 913 Glass/ Epoxy Prepeg

6. Hexcel 913 Carbon/Epoxy Prepeg.

Carbon epoxy and the glass epoxy laminates are prepared using hand layup and cured in Hot press as per the standard cure cycle. Carbon epoxy laminates of $2 \mathrm{~mm}$ thick are fabricated using carbon prepeg with 8 layers (each $0.25 \mathrm{~mm}$ thick) and has $45 \%$ of resin content. similarly the glass epoxy laminates of $2 \mathrm{~mm}$ thick are fabricated using glass prepeg consisting 8 layers( each $0.25 \mathrm{~mm}$ thick) and has $37 \%$ resin content. Layers are staggered one after the other in $0 / 90$ deg.oreintations as per the standard layup sequence. The ILSS specimens are prepared from the cured laminates as per the DIN 29971 standards.

The polypropylene thin films of thickness 50 microns are available in the form of rolls as shown in the Fig.1, The density of this material is $0.946 \mathrm{~g} / \mathrm{cm}^{3}$ and the melting point is about 130-171 deg.C.

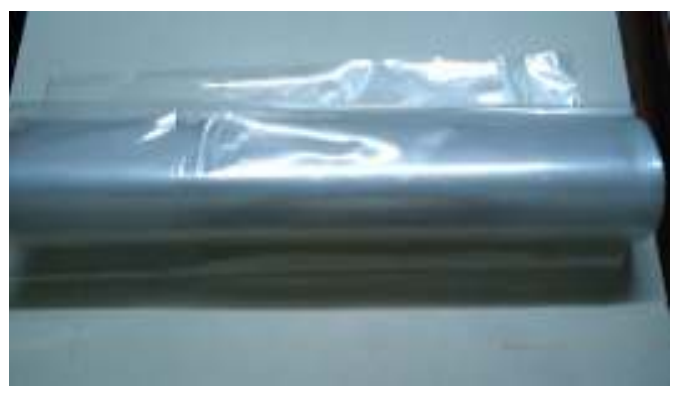

Figure 1. Polypropylene film in the form of rolls.

The dry fibers of glass are cut in to 200 X $200 \mathrm{~mm}$ size and are laid alternatively after each layer of polypropylene film to fabricate a laminate of $2 \mathrm{~mm}$ thickness as show in the Fig. 2 similarly carbon and jute polypropylene laminates of $2 \mathrm{~mm}$ thickness are prepared. The details of the resin and fiber percentage are as shown in the Table1.

After layup the layers are kept in between the platens of the Hot press and cured at 170 deg.C by applying pressure up to $80 \mathrm{~N} / \mathrm{cm}^{2}$. It was observed the layers are distorted as shown in the Fig. 3 and the laminate is not cured properly.

The distortion of the layers in trial 1 . is due to improper clamping of layers, since as the polypropylene film gets gel at elevated temperature 
the fibers tends to slide each other and hence the layers are placed in between the steel plates with clamping and then cured in the press, shown in the Fig. 4 and 5.

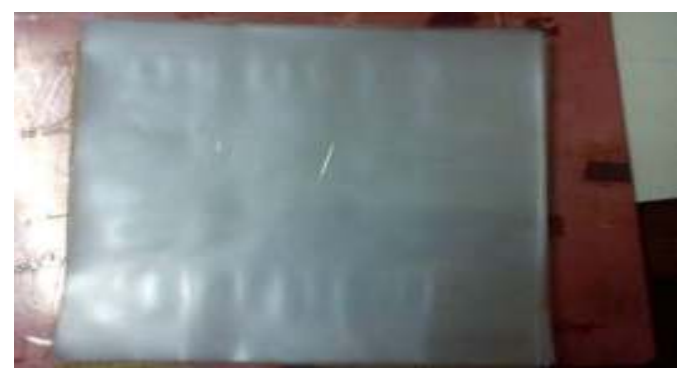

Figure 2. Layup of Polypropylene and Glass dry fibers

Table1. Details of the resin and fiber percentage

\begin{tabular}{|c|c|c|c|}
\hline LAMINATE & $\begin{array}{c}\text { Wt. of PP } \\
\text { Resin. } \\
\text { (Kg) }\end{array}$ & $\begin{array}{c}\text { Wt. of Fiber } \\
\text { (Kg) }\end{array}$ & $\begin{array}{c}\text { \% of } \\
\text { Resin }\end{array}$ \\
\hline Carbon/ PP & 0.026 & 0.061 & 42 \\
\hline Glass /PP & 0.034 & 0.07 & 48 \\
\hline Jute/PP & 0.025 & 0.04 & 62 \\
\hline
\end{tabular}

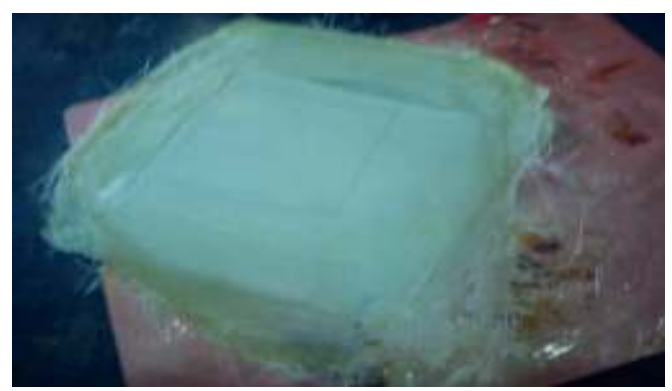

Figure 3. Distortion of layers resulting improper curing.

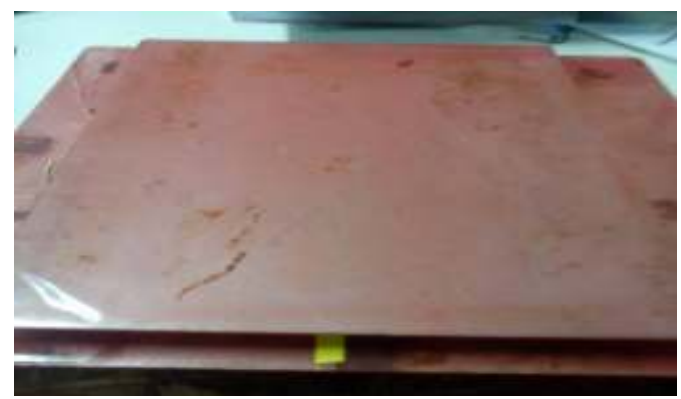

Figure 4. Clamping of layers before curing.

After curing in hot press the laminates are trimmed at the edges to the exact size of $200 \mathrm{X} 200$ $\mathrm{mm}$ as shown in the Fig. 6,7 and 8 and these laminates are sent to ultrasonic testing to test the internal defects and compaction level.

Ultrasonic testing is the most widely used non-destructive inspection method for the examination of composites. On microscopically homogenous materials (i.e. non composites) it is commonly used in the frequency range $20 \mathrm{KHZ}$ to 20 MHZ, The composite laminates were tested by Through Transmission technique, also known as $\mathrm{C}-$ scan technique.Through-transmission is an ultrasonic technique that typically uses two transducers: an emitter and a receiver, the receiver being placed on the opposite side of the component and facing the transmitting probe. It is sometimes referred to as the 'obscuration' technique because it measures total attenuation within the material caused by features that 'obscure' the beam. Comparisons can be made of the attenuation between different specimens and between different regions of the same specimen.

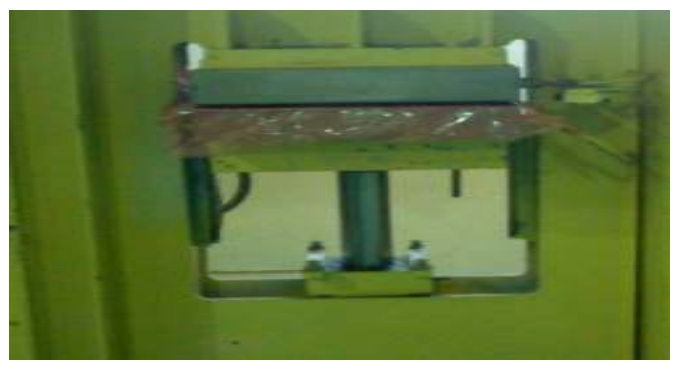

Figure 5. Curing arrangement in Hot Platen Press.

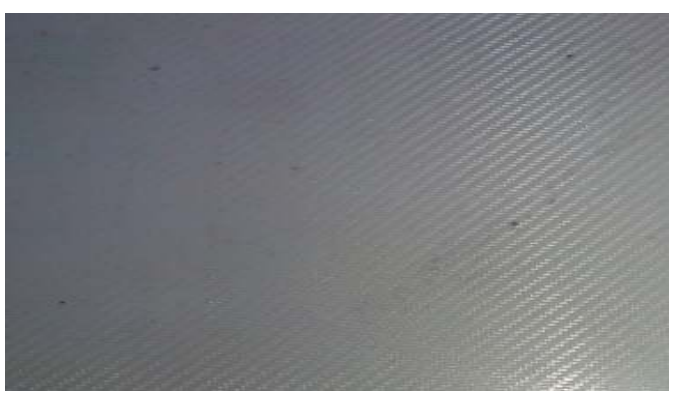

Figure 6. Cured Glass/polypropylene Laminate.

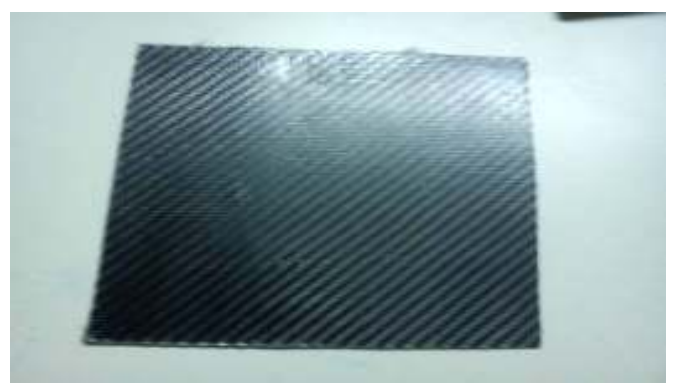

Figure 7. Cured carbon/polypropylene Laminate. 


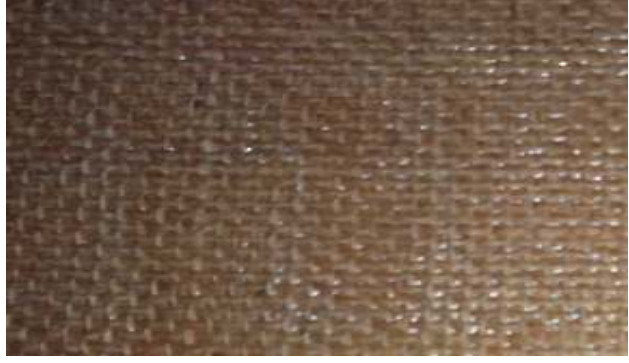

Figure 8. Cured Jute/polypropylene Laminate.

The ultrasound is coupled to the specimen through a jet of water projected onto its surface. The probe/sample distance can be as long as the water column, and since this acts as the ultrasound guide, small changes in the probe alignment or surface orientation can be tolerated. The schematic of a $\mathrm{C}$ scan setup is depicted in Fig. 9.

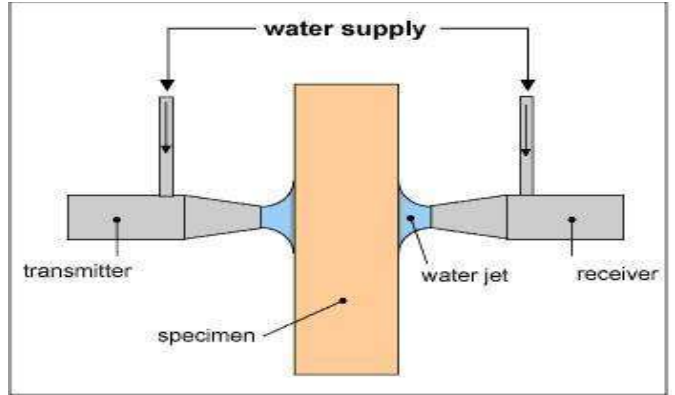

Figure 9. Ultrasonic 'C' Scan set up.

Ultrasonic ' $C$ ' Scan was carried out for all the laminates and observed the ultrasonic attenuation level for the carbon /epoxy and glass epoxy laminates are within the limits whereas the laminates fabricated with polypropylene exhibits gain in attenuation levels resulting poor compaction as indicated by the red marks in the profile view in Fig. 11 and 13.

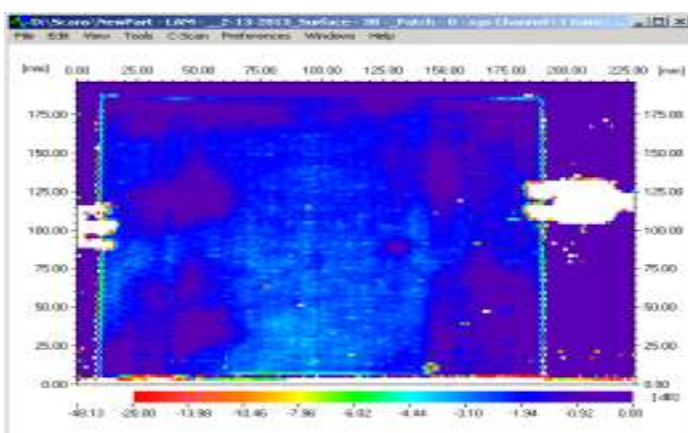

Figure 10. 'C' scan profile view of Glass/epoxy laminate
The glass epoxy and the carbon epoxy laminates exhibits good compaction and absence of voids resulting better strength and mechanical properties. Since the epoxy matrix cross links with the fiber during polymerization in curing process. The ' $C$ ' Scan profile views of these laminates are shown in Fig. 10 and 12.

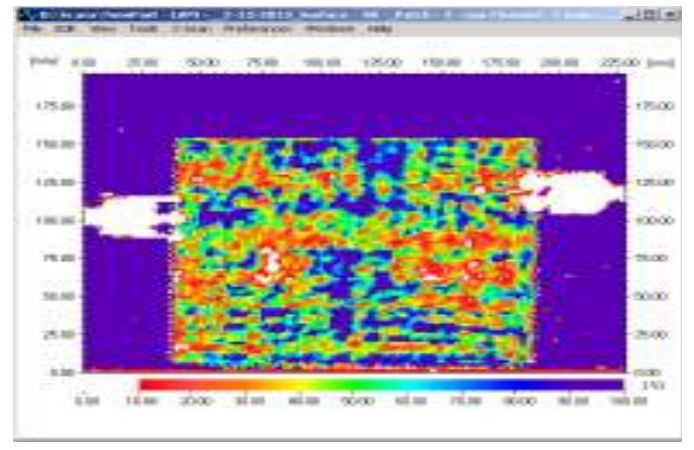

Figure11. 'C' scan profile view of Glass/PP laminate

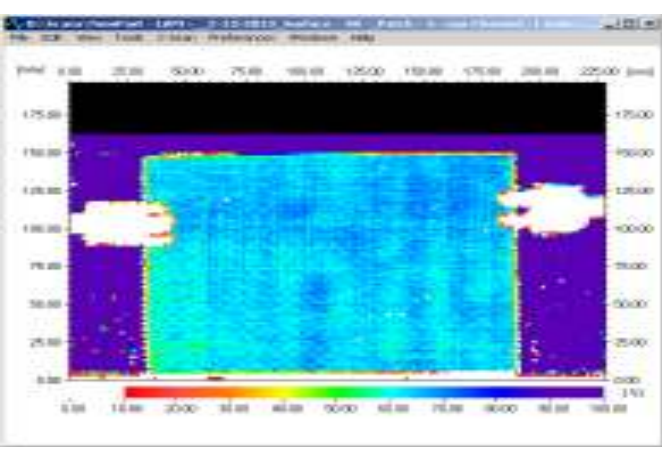

Figure 12. 'C'scan profile view of Carbon/Epoxy laminate

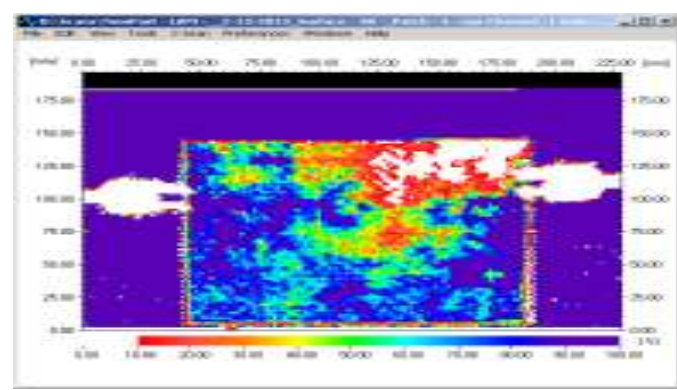

Figure 13. 'C'scan profile view of Carbon/PP laminate

\section{ILSS TESTING}

The specimens are prepared from the cured laminates with the dimensions of $5 \mathrm{t} \times 10 \mathrm{t}$ for InterLaminar Shear Strength (ILSS) tests as per the DIN 29971 standards as shown in Fig. 14. 


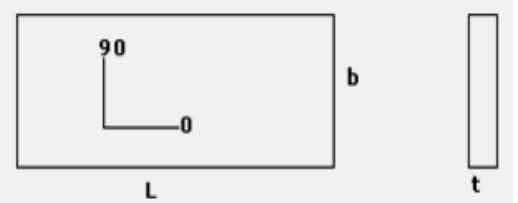

(Length $\mathrm{L}=20 \mathrm{~mm}$, Width $\mathrm{b}=10 \mathrm{~mm}$, thickness $\mathrm{t}=2 \mathrm{~mm}$ )

Figure 14. ILSS Specimen dimensions as per DIN 29971 standards.

The ILSS (InterLaminar Shear Strength) signifies the compaction strength or the bonding strength between the fibers and the matrix ( resin) in the composite structure, generally it is calculated using the formula

ILSS $=-\{\mathrm{F} /(\mathrm{b} \times \mathrm{t})\} \mathrm{N} / \mathrm{mm}$

where, $\mathrm{F}=$ Peak Load $(\mathrm{N}), \mathrm{b}=$ Width of the specimen $(\mathrm{mm}), \& \mathrm{t}=$ Thickness of the specimen $(\mathrm{mm})$.

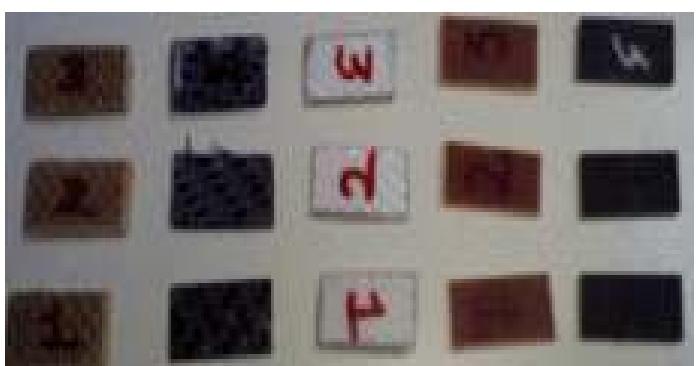

Figure 15. ILSS Test specimens as per DIN standards.

\section{RESULTS AND DISCUSSIONS}

The ILSS values of the laminates tested are tabulated in the table 2. It is observed that the laminates prepared with polypropylene matrix depict low ILSS values and these values are 7 to 8 times low as against the epoxy matrix laminates as shown in the Fig. 16.

Table 2. Details of Inter Laminar Shear Strength values.

\begin{tabular}{|c|c|}
\hline Material & Avg. ILSS ( Mpa) \\
\hline Carbon / PP & 7.79 \\
\hline Glass/PP & 6.75 \\
\hline Jute/PP & 5.90 \\
\hline Glass/Epoxy & 52.84 \\
\hline Carbon/Epoxy & 62.97 \\
\hline Jute/ Epoxy & 13.86 \\
\hline
\end{tabular}

The Interlaminar shear strength signifies the stresses acting on the interface of two adjacent plies in the composite laminates. The measured ILSS are very low in thermoplastic composites made of polypropylene. This is due to poor compaction between the fiber and the resin that owe to low stiffness and strength. Whereas the thermoset composite laminates have better compaction and crosslinking between the fiber and the resin molecules thereby the compaction is better and pose excellent strength and stiffness. In case of the jute /PP and the Jute/epoxy laminates the variation is less compared to other synthetic fibers since the jute exhibits less reinforcement strength and with stands low loads compared to others, comparitivley the jute /epoxy shows almost 2.2 times better strength than the jute/pp.

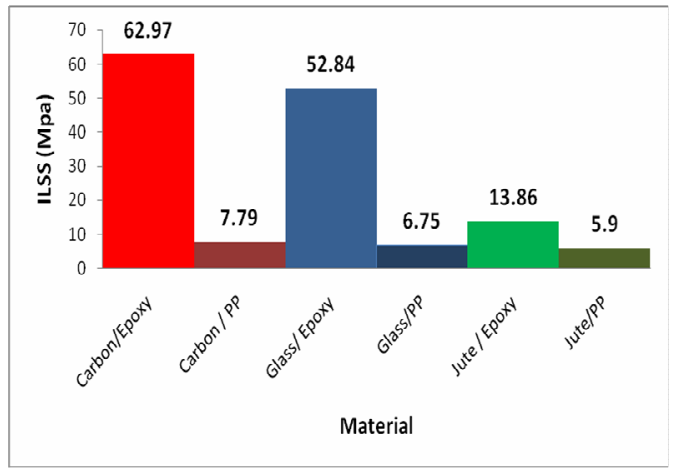

Figeue 16. shows the comparison in Avg. ILSS values of Epoxy matrix and polypropylene matrix specimens.

\section{Water Absorption Test}

The water absorption test covers the determination of the relative rate of absorption of water by composites when immersed. This test method is intended to apply to the testing of all types of resins. This is done to determine the effects of exposure to water or humid conditions.

In this test, the samples of $20 \times 10 \times 2 \mathrm{~mm}$ were cut from the laminates. These samples were air dried and then immersed in $50 \mathrm{ml}$ of water. The specimens were taken out of the water at regular intervals of time, wiped with tissue paper to remove surface water droplets, re-weighed and immediately immersed in the water again. The water absorption test was conducted according to ASTM D570 method.

Three specimens for each sample were used and the average values were reported. The percentage of water absorption (WA) was calculated by the weight difference between the samples exposed to water and the dried samples according to the following equation.

$$
\text { WA }(\%)=\{(\mathrm{Mn}-\mathrm{Mo}) / \mathrm{Mo}\} \times 100
$$

where, Mo - Initial mass of the sample (in grams)

Mn - Mass of the sample after ' $n$ ' days (in grams)

The water absorption test results of the test specimens are tabulated below in the Table 3 . 
Table 3. Details of the water absorption test after

\begin{tabular}{|l|l|l|l|}
\hline \multirow{2}{*}{ Laminate } & $\begin{array}{c}\text { Initial } \\
\text { Mass } \\
\text { gms }\end{array}$ & $\begin{array}{c}\text { Final Mass } \\
\text { after 24 Hrs. } \\
\text { gms }\end{array}$ & $\begin{array}{c}\text { \% of } \\
\text { water } \\
\text { absorption }\end{array}$ \\
\hline $\begin{array}{l}\text { Carbon } \\
\text { /PP }\end{array}$ & 0.6472 & 0.6872 & 6.18 \\
\hline $\begin{array}{l}\text { Carbon } \\
\text { /Epoxy }\end{array}$ & 0.7778 & 0.7797 & 0.24 \\
\hline Glass/PP & 0.8129 & 0.8324 & 2.4 \\
\hline $\begin{array}{l}\text { Glass } \\
\text { /Epoxy }\end{array}$ & 0.8905 & 0.8962 & 0.64 \\
\hline Jute/PP & 0.6022 & 0.837 & 39 \\
\hline $\begin{array}{l}\text { Jute } \\
\text { /Epoxy }\end{array}$ & 0.7365 & 0.8695 & 18.06 \\
\hline
\end{tabular}

It is observed that the laminates made of polypropylene absorb more moisture compared to the epoxy matrix laminates. As a matter of fact the jute fibers absorbs more moisture and found the percentage of water absorption is more in both the cases. Hence generally jute fiber polymers are not preferred for the parts exposed directly to the atmosphere.

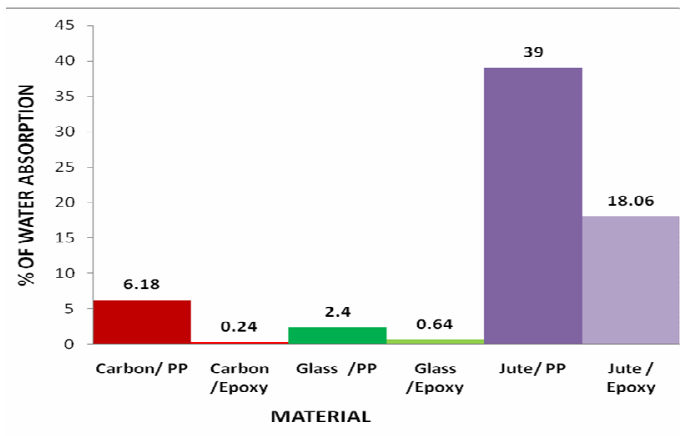

Figure 17. water absorption comparative analysis chart.

\section{CONCLUSIONS}

- The results found that the laminates cured in press exhibits poor compaction due to absence of vacuum and hence it can be cured in an autoclave under pressure \& vacuum to achieve better bonding and strength.

- The Ultrasonic ' $C$ ' scan results of the laminates indicates that Polypropylene had not bonded with the fibers as effectively as Epoxy matrix.

- Inter laminar shear tests indicated an increase in the maximum Load and the Inter laminar shear stress with an increase in resin content.

- The ILSS values of the polypropylene matrix specimens are 7-8 times lower as against the Epoxy matrix specimens and hence these materials are suitable only for interior low load bearing components like, dashboards, cabinets etc, eventually these parts are to be painted so to avoid moisture and thermal degradation.

- It was inferred from the Water absorption test that the polypropylene thermoplastic Composites are more prone to moisture.

- The Jute fibers absorb more moisture than the synthetic fibers, when used as reinforcement for Epoxy as well as Polypropylene.

- Polypropylene matrix fiber composites can be used only for interior and low strength aerospace parts as it has an advantage of reusability and reform nature.

\section{REFERENCES}

1. D.A Archibald, J.W. Shwarz, J.L. Wanamaker, 1989, Proceedings of the American Society for Composites, 4th Tech. Conf., pp 593-601.

2. J.R. Krone and J.H. Walker, 1989, "Composites Applications : The Future Is Now", SME Publications pp 112-124 (1989)

3. R.B. Ostrom, S.B. Koch, D.L. Wirz-Safranek, 1989, SAMPE Quarterly, October, pp 39-45.

4. S. Beland, 1990, High Performance Thermoplastic Resins and their Composites, Noyes Publications, pp 136-151.

5. U. Beier, F. Fischer, H. Spanner, T. Roser and W. Buchs, 2008, "Mechanical performance of carbon fiber-reinforced composites based on preforms stitched with innovative low-melting temperature and matrix soluble thermoplastic yarns", Composites Part A: Applied Science and Manufacturing, Vol. 39, No. 9, pp. 1572-1581.

6. Katsiropoulos Ch.V., Pantelakis Sp.G. and Meyer B.C., 2009, "Mechanical behavior of Non-crimp Fabric PEEK/C Thermoplastic composites", Theoretical and Applied Fracture Mechanics, Vol. 52, No. 2, pp. 122-129.

7. Mahieux C.A., 2001, "Cost effective manufacturing process of thermoplastic matrix composites for the traditional industry: the example of a carbon fiber reinforced thermoplastic flywheel", Composite Structures, Vol. 52, No. 3, pp. 517-521. 8. Vieille B., Albouy W., Chevalier L., and Taleb L., 2012, "About the influence of stamping on thermoplastic-based composites for aeronautical applications", Composites Part B: Engineering, Vol. 45, No. 1, pp. 821-834.

9. Pantelakis Sp. G., Katsiropoulos Ch.V., Labeas G.N. and Sibios H., 2009, "A concept to optimize quality and cost in thermoplastic composite components applied to the production of Helicopter canopies", Composites Part A: Applied Science and Manufacturing, Vol. 40, No. 5, pp. 595-606.

10. Mallick P.K., 1997, “Composites Engineering Handbook," Marcel Dekker Inc., New York, pp. 549-579. 